Genome Biology

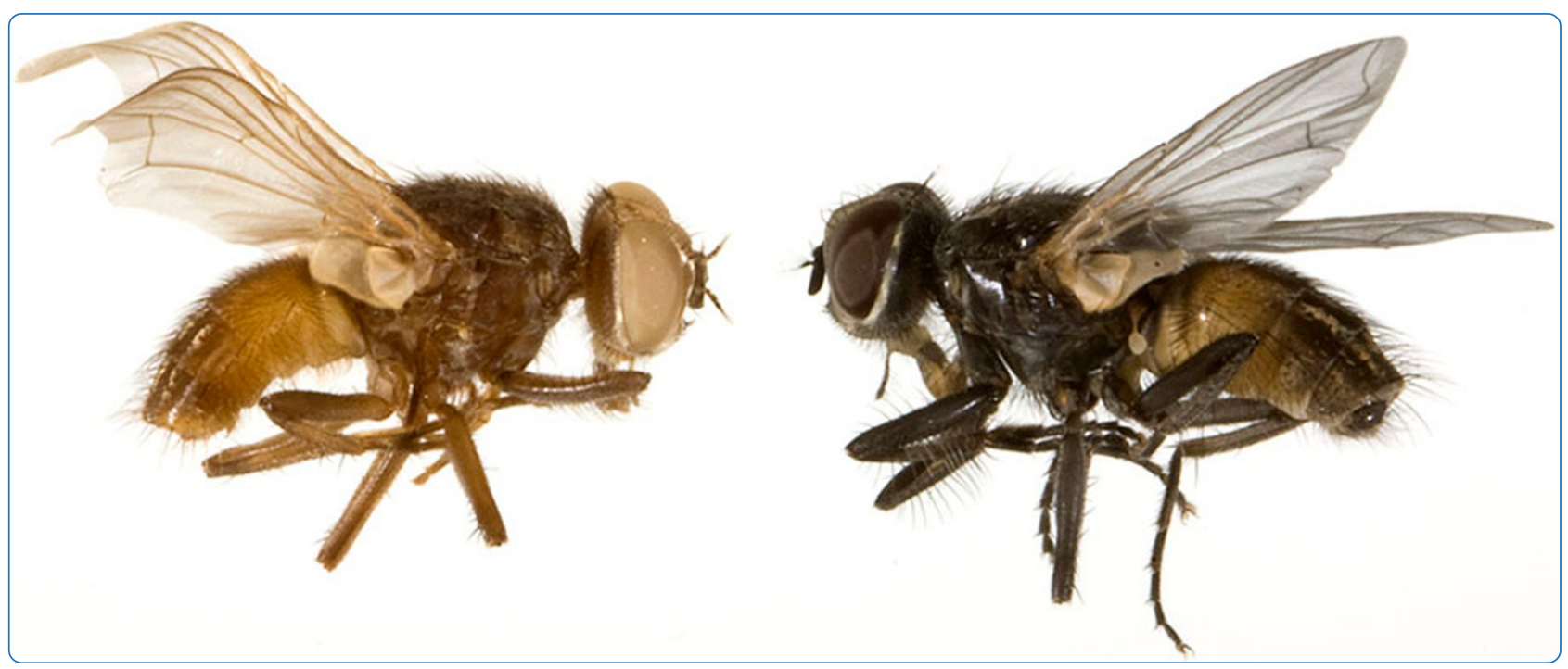

Genome of the house fly, Musca domestica L., a global vector of diseases with adaptations to a septic environment

Scott et al.

() Biomed Central 


\title{
Genome of the house fly, Musca domestica L., a global vector of diseases with adaptations to a septic environment
}

\author{
Jeffrey G Scott ${ }^{1 *}$, Wesley C Warren², Leo W Beukeboom³ ${ }^{3}$ Daniel Bopp ${ }^{4}$, Andrew G Clark ${ }^{5}$, Sarah D Giers ${ }^{6}$, \\ Monika Hediger ${ }^{4}$, Andrew K Jones ${ }^{7}$, Shinji Kasai ${ }^{1}$, Cheryl A Leichter ${ }^{1}$, Ming Li ${ }^{8}$, Richard P Meisel ${ }^{9}$, Patrick Minx ${ }^{2}$, \\ Terence D Murphy ${ }^{10}$, David R Nelson ${ }^{11}$, William R Reid ${ }^{8}$, Frank D Rinkevich ${ }^{1}$, Hugh M Robertson ${ }^{6}$, \\ Timothy B Sackton ${ }^{12}$, David B Sattelle ${ }^{13}$, Francoise Thibaud-Nissen ${ }^{14}$, Chad Tomlinson ${ }^{2}$, Louis van de Zande ${ }^{3}$, \\ Kimberly KO Walden ${ }^{6}$, Richard K Wilson ${ }^{2}$ and Nannan Liu ${ }^{8}$
}

\begin{abstract}
Background: Adult house flies, Musca domestica L., are mechanical vectors of more than 100 devastating diseases that have severe consequences for human and animal health. House fly larvae play a vital role as decomposers of animal wastes, and thus live in intimate association with many animal pathogens.

Results: We have sequenced and analyzed the genome of the house fly using DNA from female flies. The sequenced genome is $691 \mathrm{Mb}$. Compared with Drosophila melanogaster, the genome contains a rich resource of shared and novel protein coding genes, a significantly higher amount of repetitive elements, and substantial increases in copy number and diversity of both the recognition and effector components of the immune system, consistent with life in a pathogen-rich environment. There are 146 P450 genes, plus 11 pseudogenes, in M. domestica, representing a significant increase relative to $D$. melanogaster and suggesting the presence of enhanced detoxification in house flies. Relative to D. melanogaster, M. domestica has also evolved an expanded repertoire of chemoreceptors and odorant binding proteins, many associated with gustation.
\end{abstract}

Conclusions: This represents the first genome sequence of an insect that lives in intimate association with abundant animal pathogens. The house fly genome provides a rich resource for enabling work on innovative methods of insect control, for understanding the mechanisms of insecticide resistance, genetic adaptation to high pathogen loads, and for exploring the basic biology of this important pest. The genome of this species will also serve as a close out-group to Drosophila in comparative genomic studies.

\section{Background}

House flies, Musca domestica L. (Diptera: Muscidae), are ubiquitous and transmit more than 100 human and animal diseases [1-3], including bacterial infections such as salmonellosis, anthrax, ophthalmia, shigellosis, typhoid fever, tuberculosis, cholera and infantile diarrhea; protozoan infections such as amebic dysentery; helminthic infections such as pinworms, roundworms, hookworms and tapeworms; as well as viral and rickettsial infections.

\footnotetext{
*Correspondence: jgs5@cornell.edu

'Department of Entomology, Comstock Hall, Cornell University, Ithaca, NY 14853, USA

Full list of author information is available at the end of the article
}

House flies can spread a deadly strain of Escherichia coli [4] and transmit life threatening antibiotic-resistant bacteria $[5,6]$, which constitute an ever increasing threat in hospitals and other healthcare facilities [7-10]. Flies also transmit pathogens responsible for eye diseases such as trachoma and epidemic conjunctivitis, and infect wounds or skin with diseases such as cutaneous diphtheria, mycoses, yaws and leprosy [2]. Fly-transmitted trachoma alone causes 6 million cases of childhood blindness each year [11]. The mobility of house flies, their regular contact with excreta, carcasses, garbage and other septic matter, and intimate association with animal pathogens and humans all contribute to their roles in transmission of these diseases 
$[1,2]$. House fly larvae play a vital role in ecosystems as decomposers of animal wastes. This represents a unique niche, relative to other insects that have had their genomes sequenced.

House flies are always found in association with humans and human activities, following the spread of Homo sapiens across the planet [12]. They are also one of the most serious pests at animal production facilities worldwide. Insecticides have been used extensively for controlling house flies for a century and this pest has shown a remarkable ability to rapidly evolve resistance. This led to house flies being one of the primary insects used for studies on insecticide resistance and toxicology.

The house fly has been a model system for studies of insect olfaction $[13,14]$ and (Z)-9-tricosene plays an important role in inter-sex communication and mate selection in house flies. New attractants would be valuable for baits in management systems $[15,16]$ and could lead to a reduction in insecticide use for house fly control.

Nasonia vitripennis is a parasitoid of the house fly (Nasonia is sold commercially for fly control) and the Nasonia genome has been sequenced [17]. Having the genome of both the parasitoid (Nasonia) and the host (M. domestica) will allow unprecedented insights into the molecular mechanisms of host-parasitoid interaction.

The Diptera clade has radiated into over 120,000 known species since its origin in the late Jurassic. $M$. domestica is well placed within the Diptera to maximize the utility of sequence data for comparison between existing dipteran genomes [18]. Multiple, deeply divergent comparisons within the order allow identification of lineage effects on rates and patterns of genomic diversity. These comparisons become more powerful in elucidating genome evolution as the phylogenetic context is broadened. Given the well centered position between Drosophila and mosquitoes, the Musca genome is nearly ideal for leveraging analysis and annotation of the mosquito genomes [18].

M. domestica has a well described linkage map for the five autosomes (I to $\mathrm{V}$ ) and two sex chromosomes ( $\mathrm{X}$ and Y) [19-23]. In the house fly, male sex is determined by a dominant factor, $\mathrm{M}$, which is located on the $\mathrm{Y}$ chromosome in 'standard' populations. Thus, males are $\mathrm{XY}^{\mathrm{M}}$ and females are XX $[24,25]$. This is believed to be the ancestral state of sex determination in house flies [26,27]. However, $\mathrm{M}$ can be located on one or more of the five autosomes [28-34] or even rarely on X [26,35]. The former M factors are referred to as 'autosomal M' and both males and females in carrier populations typically have the XX genotype $[24,26,29,36]$. Autosomal $M$ factors act similarly to $Y$ chromosome $\mathrm{M}$ factors in determining maleness, by prohibiting the female specific splicing of the transformer (Md-tra, previously F) primary transcript $[28,35]$. In autosomal $\mathrm{M}$ populations from different continents, especially those having males with multiple $\mathrm{M}$ factors, a $M d$-tra variant was found, $M d$-tra ${ }^{D}$ (previously $F^{D}$ ), which acts as a dominant female determiner. It allows females to be produced even in the presence of multiple copies of $M$ (or a homozygous $\mathrm{M}$ ) and effectively makes females the heterogametic sex $\left(\mathrm{M} / \mathrm{M} ; M d\right.$-tra ${ }^{D} / M d-$ tra $\left.^{+}\right)$, and males the homogametic sex (M/M; Md-tra / Md-tra ${ }^{+}$) [28,34]. The genome sequence will accelerate progress in understanding many of these and other aspects of house fly biology.

\section{Results and discussion}

\section{Sequencing and assembly}

Genomic DNA of a pool of six adult female flies was sequenced and assembled to a size of $0.691 \mathrm{~Gb}$, comprising 20,487 scaffolds (N50 contig, $12 \mathrm{~kb}$; N50 scaffold, $226 \mathrm{~kb})$. Scaffolds ranged in length up to a maximum of $2.29 \mathrm{Mb}$ (Table 1). This genome size of $0.691 \mathrm{~Gb}$ is $81 \%$ of the size estimated using kmer frequency plus depth of coverage calculations, $75 \%$ of the size determined spectrophotometrically [37] and 200\% of the size estimated using quantitative PCR [38], respectively. More than half (52\%) of the $M$. domestica genome is composed of interspersed repeats, suggesting a novel genome evolution trajectory compared with Drosophila melanogaster (Additional file 1). A majority of these repeat elements (representing 25\% of the genome) are those that transpose by DNA excision and repair, class II or DNA transposons. Using the NCBI annotation pipeline and RNA-seq transcript evidence, we predicted a total of 14,180 protein-coding genes and 1,165 non-coding genes (Table 2). Alignment of $550 \mathrm{M}$. domestica transcripts (GenBank) to the assembly showed that $95 \%$ align over at least $90 \%$ of their length, and of 248 aligned universal single copy orthologs (CEGMA), 98\% were complete, suggesting that the assembly has captured most of the protein-coding genes in the genome. A measure of aggregate transcript coverage by alignment of whole body and larva RNA-seq data to our M. domestica reference was $66 \%$. This measure of transcript coverage varies (66 to $94 \%$ ) among insect genomes as a result of assembly contiguity, dictated by repeat composition (Additional file 2). The average protein identity

Table 1 House fly genome assembly scaffold length distribution

\begin{tabular}{ll}
\hline Scaffold length & Scaffold count \\
\hline$>1 \mathrm{Mb}$ & 35 \\
$250 \mathrm{~kb}$ to $1 \mathrm{Mb}$ & 604 \\
100 to $250 \mathrm{~kb}$ & 1,082 \\
10 to $100 \mathrm{~kb}$ & 4,640 \\
5 to $10 \mathrm{~kb}$ & 2,584 \\
2 to $5 \mathrm{~kb}$ & 6,000 \\
$<2 \mathrm{~kb}$ & 5,542 \\
\hline
\end{tabular}


Table 2 Genic characteristics of the house fly genome

\begin{tabular}{lll}
\hline Feature & Count & Mean length \\
\hline Genes & 15,345 & 13,553 \\
Transcripts & 18,779 & 2,097 \\
mRNA & 17,508 & 2,221 \\
tRNA & 947 & 74 \\
Single exon transcripts & 2,566 & 797 \\
Exons & 67,886 & 431 \\
Introns & 52,875 & 3,889 \\
\hline
\end{tabular}

in comparison to D. melanogaster (RefSeq) was $64 \%$. In addition to the RNA-seq data generated in our study, we also compared the $M$. domestica genome with a previously published transcriptome of $M$. domestica [39]. Of the 6,159 transcripts previously reported, 6,053 had matches in the $a b$ initio predicted genes in $M$. domestica when compared using BLASTn [40]. The average percent identity was $98.7 \pm 0.02 \%$ and ranged from 75.2 to $100 \%$, identical to the $a b$ initio predicted gene set (Additional file 3). The remaining 106 transcripts previously reported [39] were further compared with the genome using Exonerate [41] and had, on average, $97.6 \pm 0.9 \%$ identity, ranging from 38.6 to $100 \%$ identical (Additional file 3).

We grouped the 14,180 predicted protein-coding genes in $M$. domestica into 10,427 orthologous groups based on homology to $D$. melanogaster. Each orthologous group contains at least one $M$. domestica protein, and can be assigned to one of three categories: single copy ortholog, for groups that contain a single $M$. domestica protein and a single $D$. melanogaster protein, conserved paralog, for groups that contain both $M$. domestica and $D$. melanogaster proteins, but are not single copy in both species, and lineage-restricted, for groups that contain only $M$. domestica proteins. Of the 14,180 predicted protein-coding genes, 7,006 (49\%) are single copy orthologs of D. melanogaster proteins, 5,240 (37\%) are in conserved paralogous groups (mean size in $M$. domestica: 2.88 proteins), and the remaining 1,934 (14\%) are lineage-restricted and lack homologs in D. melanogaster.

\section{Gene ontology}

The most abundant Gene Ontology (GO) biological processes represented by house fly genes were single-organism process $(12.1 \%)$, cellular process $(12.0 \%)$, metabolic process (11.1\%) and biological regulation (10.8\%; Figure S1A in Additional file 4). The most abundant cellular components were cell $(32.6 \%)$ and organelle (29.2\%; Figure S1B in Additional file 4). The most abundant molecular processes were binding (48.1\%) and catalytic activity (28.9\%; Figure S1C in Additional file 4). Overall, the distribution of genes within $\mathrm{GO}$ classifications was very similar between
M. domestica and D. melanogaster (Additional file 5). Within the biological processes classification, the most notable difference was the more than two-fold greater percentage of genes in M. domestica associated with 'growth'. Within the cellular components classification $M$. domestica had an approximately two-fold greater percentage of genes in the 'membrane', and 'membrane-enclosed lumen' categories (relative to $D$. melanogaster). $M$. domestica also had a lower percentage of genes in the 'cell' category, relative to $D$. melanogaster. There were no remarkable differences between $M$. domestica and $D$. melanogaster in the percentage of genes in the molecular functions categories (Additional file 5).

\section{Immune-related genes}

We identified 771 putative immune-related genes in the house fly, of which 416 have direct homology (see Materials and methods) to known or putative $D$. melanogaster immune-related proteins, and the remaining 355 are identified based on hidden Markov model (HMM) queries. As in other insects, these genes encode proteins with several functions: recognition proteins that identify pathogen-associated molecular patterns, proteins that belong to signaling pathways that activate the transcriptional response to infection, and effector molecules that kill pathogens.

Previous work, primarily in Drosophila, has identified four primary signaling pathways involved in the systemic transcriptional response to bacterial and fungal infection: the Toll, imd, JAK/STAT, and JNK pathways [42,43]. The $M$. domestica genome possess the full complement of signal transduction or signal modulation components of these pathways, and the vast majority are conserved as single copy orthologs between $M$. domestica and D. melanogaster. It appears likely, therefore, that immune signaling in $M$. domestica is substantially similar to immune signaling in D. melanogaster.

In contrast to the signaling pathways, both recognition and effector components of the immune system show substantial increases in copy number and genic diversity in $M$. domestica compared with $D$. melanogaster, suggesting the possibility that $M$. domestica possesses a more robust immune response to diverse pathogens encountered in the pathogen-rich environment in which it lives. In other insects, a variety of cell-surface and secreted proteins involved in recognition of pathogens have been identified, including peptidoglycan recognition proteins and beta-glucan binding proteins (also known as GNBPs in Drosophila), which are upstream of the main signaling pathways [44], and a variety of receptors likely involved in phagocytosis, including Nimrods, thioester-containing proteins (Teps) and scavenger receptors $[45,46]$. Of these, there are striking expansions in copy number of Nimrods 
and Teps in particular. The Nimrod gene family is one of the more variable in copy number among the sequenced Drosophila species [47], a trend that is continued in the more divergent comparison to $M$. domestica (17 Nim-containing proteins in $M$. domestica and 11 in $D$. melanogaster; only $8.7 \%$ of gene families have a greater degree of expansion in $M$. domestica). Even more striking is the expansion of the Tep family (Figure 1), which has 19 members in M. domestica and only 6 in D. melanogaster. The Tep $1 / 2$ gene family specifically has expanded dramatically in $M$. domestica: this family has 2 members in D. melanogaster but 16 members in $M$. domestica, which is the 15th largest species-specific expansion in the $M$. domestica genome (Additional file 1). In addition, the $M$. domestica genome contains three lineage-specific genes that encode proteins with Tep-like domains (identified by HMM), but which are not clearly homologous to any characterized $D$. melanogaster Teps.
In $M$. domestica, similar to recognition proteins, the effector molecule repertoire is also significantly expanded. $M$. domestica shares four antimicrobial families with $D$. melanogaster, the attacins, diptericins, cecropins, and defensins $(D$. melanogaster also possesses one drosocin, one metchnikowin, and seven drosomycins that are not identifiable in the $M$. domestica genome), three of which have expanded relative to D. melanogaster (10 attacins in $M$. domestica, 4 in D. melanogaster; 12 cecropins in $M$. domestica, 5 in D. melanogaster (including andropin); 5 defensins in $M$. domestica, 1 in D. melanogaster; 2 diptericins in $M$. domestica, 2 in $D$. melanogaster). Even including the 9 antimicrobial peptides in Drosophilaspecific families, $M$. domestica has a significantly enlarged antimicrobial peptide (AMP) repertoire (29 versus 19). AMP gene families are known to evolve very rapidly [48], and it is likely that novel effectors remain to be discovered in M. domestica (as in mosquitos [49], bees [50], and

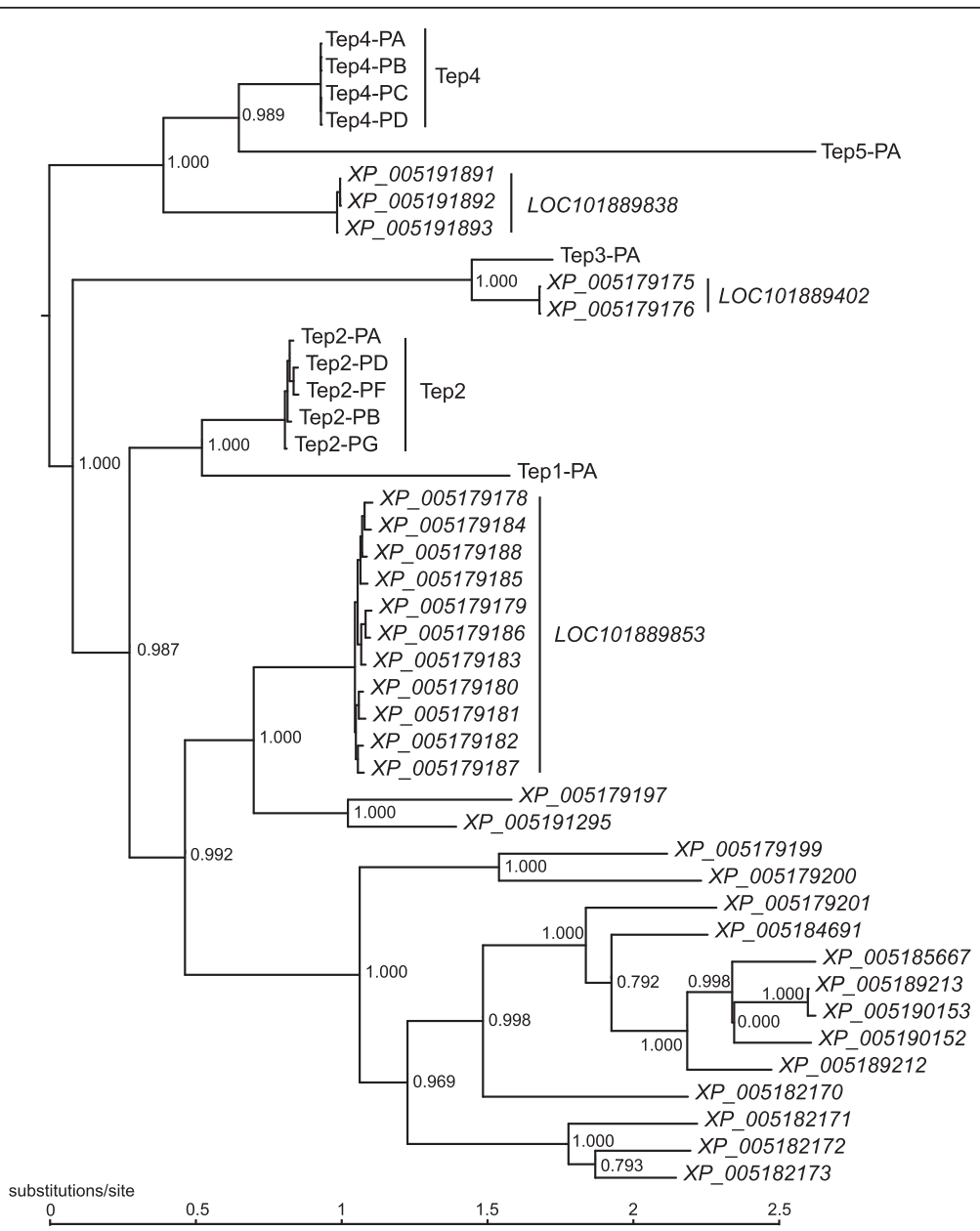

Figure 1 Tep phylogeny. Maximum likelihood amino acid phylogeny of $D$. melanogaster and $M$. domestica Teps. D. melanogaster proteins are labeled Tep1 to Tep5. M. domestica Teps are labeled XP_NNNNNNNNN and are shown in italics. For both species, multiple isoforms of the same gene are indicated with a bar. Branch support is the SH-like statistic estimated in phyml. The tree is rooted so as to minimize the number of duplications. 
wasps $[51,52])$, further increasing the potential diversity of the house fly AMP response.

\section{Metabolism/detoxification genes}

Three groups of enzymes are commonly associated with detoxification of xenobiotics (although they have other functions as well [53]): cytochrome P450s, esterases/ hydrolases, and conjugation enzymes. The largest group in $M$. domestica is the cytochrome P450s, for which a total of 146 genes plus 11 pseudogenes were identified (Additional file 6). This represents a significant expansion of P450s relative to D. melanogaster, which has 86 [54], and relative to Glossina morsitans, which has 72 (Additional file 7). Most of the predicted cytochrome P450 genes (135 genes) were full length while 11 genes were incomplete, or were contained within multiple predicted transcripts, six of which, CYP6A56, CYP6GV1, CYP6A36, CYP304A2, CYP310B2, and CYP313D1, had partial sequences either due to low sequence coverage or because the predicted gene spanned the edge of a supercontig (Additional file 8). One cytochrome P450 gene, CYP4D68, was predicted to have an alternative amino terminus (XM_005190900) upstream of the main cytochrome P450 predicted gene locus (XM_005190901), and four other P450s genes (CYP4D3, CYP4D4, CYP4D58, CYP4AC6) may have alternative splicing isoforms as well (Additional file 8). The remaining four cytochrome P450 genes, CYP6A6, CYP6A58, CYP6D1, and CYP4D64, were represented by more than one predicted transcript that either spanned the edges of different supercontigs or were positioned proximal to each other within the genome (Additional file 8). The expansion of cytochrome P450 genes in $M$. domestica was predominantly present within clans 3 and 4, which had 65 and 55 genes, respectively (Figure 2). The most predominant P450 families in $M$. domestica were CYP6 and CYP4, which contained 46 and 43 genes, respectively, and represented $>60 \%$ of all cytochrome P450s in the M. domestica genome. This is a

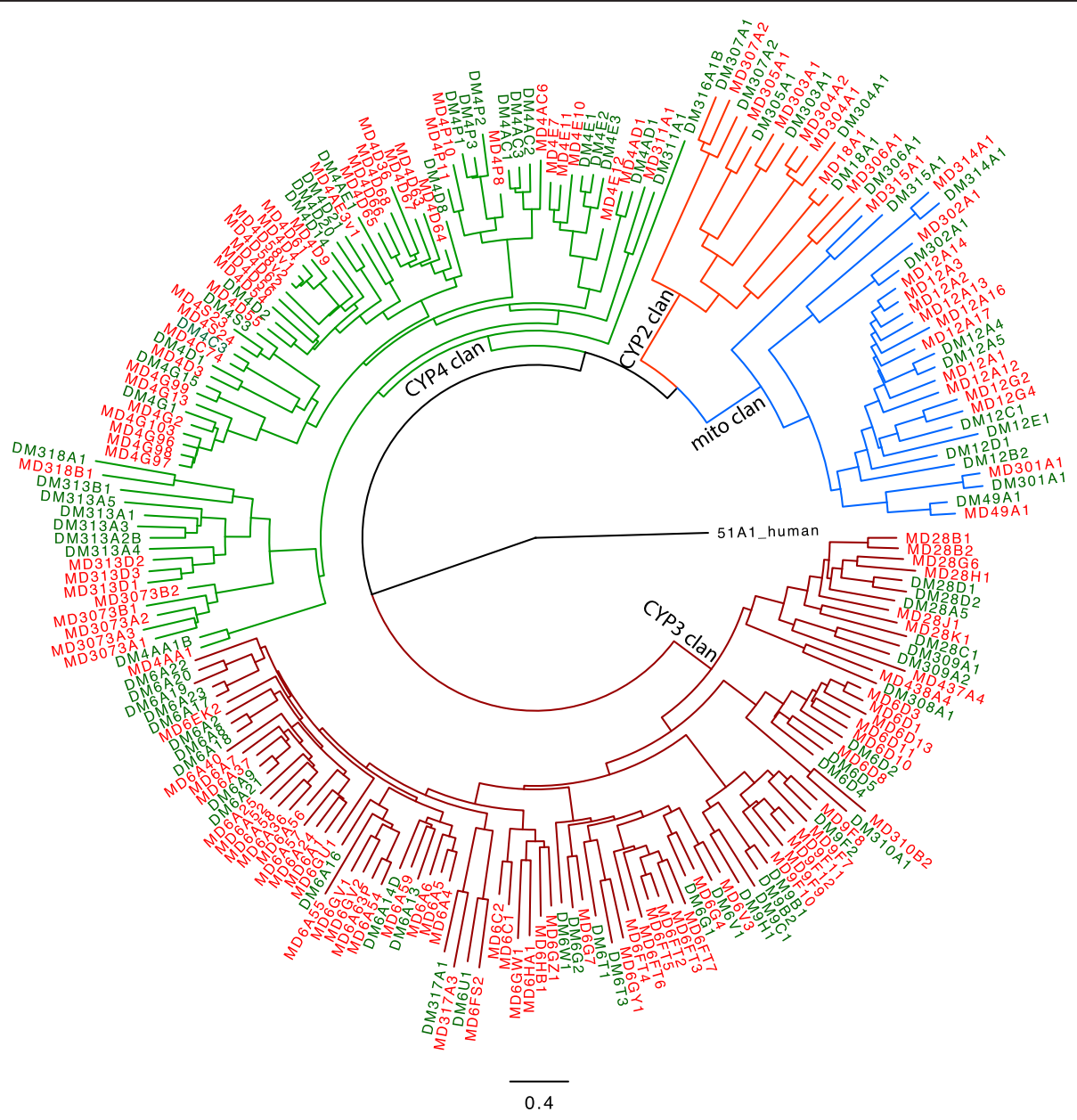

Figure 2 Neighbor-joining tree showing the phylogenetic analysis of cytochrome P450 (CYP) genes of $M$. domestica (MD, red) in relation to CYP genes from D. melanogaster (DM, green). Clustal W was used to perform multiple sequence alignment and Phylip was used to compute the tree. The tree was rooted with human CYP51 as an out-group. The four insect CYP clades are shown in different colors. Sequences for the cytochrome P450 genes and the gene names were taken from the DR Nelson P450 homepage [59]. 
similar percentage to what is present in the D. melanogaster genome, in which the genes in the CYP6 and CYP4 families account for $50 \%$ of the total cytochrome P450 genes in the genome [55]. The Halloween genes, CYP306A1 (phantom), CYP302A1 (disembodied), CYP307A2 (spookier), CYP315A1 (shadow), and CYP314A1 (shade), were identified [56], along with $C Y P 18 A 1$, which is involved in the inactivation of 20-hydroxyecdysone [57], and CYP301A1, which has recently been shown to be important for cuticle formation [58]. Taken together, the complement of cytochrome P450 genes identified in the $M$. domestica genome consist of those anticipated to be present, along with a predominance of cytochrome P450 genes from the CYP6 and CYP4 families as seen in D. melanogaster.

A total of 33 glutathione $S$-transferase (GST) genes and 3 splice variants were predicted from the M. domestica genome (Additional file 9). This is similar to the number present in D. melanogaster, which has 36 GST genes and 11 splice variants [60]. An unrooted phylogenetic analysis of the GSTs for M. domestica and D. melanogaster showed that the $M$. domestica GST genes were distributed among the different classes of cytosolic GSTs present in the D. melanogaster genome: epsilon, omega, theta, sigma, and zeta (Additional file 10). An additional four microsomal GST genes were predicted from the $M$. domestica genome, which is similar to the number of microsomal GST genes present in D. melanogaster (three genes with a total of four isoforms).

In the $M$. domestica genome, a total of 92 genes were predicted to have esterase activities, including phosphodiesterase, acetylcholinesterase, thioesterase, carboxylesterase, metallophosphoesterase, neuropathy target esterase and palmitoyl-protein thioesterase (Additional file 5). Based on the chemical reactions they catalyze, these enzymes were divided into four categories, containing a total of 39 carboxylic-ester hydrolases (EC 3.1.1), 10 thioester hydrolases (EC 3.1.2), three phosphoric-monoester hydrolases (EC 3.1.3) and 40 phosphoric-diester hydrolases (EC 3.1.4) [61].

\section{Cys-loop ligand-gated ion channels}

Members of the cys-loop ligand-gated ion channel (cysLGIC) superfamily mediate fast synaptic transmission in insects. They play key roles in behavior, such as escape responses [62], olfactory learning and memory [63], as well as regulating sleep [64]. CysLGICs consist of five homologous subunits arranged around a central ion channel [65]. Analysis of the $M$. domestica genome has revealed 23 subunit-encoding genes, which is the same complement of genes found in D. melanogaster [66] (Figure 3). Ten of these genes encode putative nicotinic acetylcholine receptor ( $\mathrm{AAChR}$ ) subunits, which consist of a core group of subunit-encoding genes ( $\alpha 1$ to $\alpha 7$ and $\beta 1$ to $\beta 2$ ) [67] that are highly conserved between insect species, four of which $(\alpha 2, \alpha 5, \alpha 6$ and $\beta 3)$ have been characterized from $M$. domestica [68-70]. The $M$. domestica genome also contains a single divergent subunit ( $\beta 3)$ that is less well conserved [70]. For nAChRs, $\alpha$ subunits are traditionally defined by the presence of two vicinal cysteine residues important for interactions with acetylcholine, while $\beta$ subunits lack this motif [71]. The putative $M$. domestica ortholog of $\mathrm{D} \beta 2$ is a non- $\alpha$ subunit (Mdom $\beta 2$; Figure 3), which is unusual considering that the orthologs of $\mathrm{D} \beta 2$ in other insect species possess the cysteine doublet and thus are $\alpha$ subunits, including Agam $\alpha 8$ from another member of the Diptera, the mosquito Anopheles gambiae [72]. The amino acid sequences and accession numbers for the cysLGICs are provided in Additional file 11.

The house fly cysLGIC superfamily also includes Rdl [73], GRD and LCCH3, which form ion channels gated by $\gamma$-aminobutyric acid (GABA) [74], a glutamate-gated chloride channel (GluCl) [73], two histamine-gated chloride channels (HisCl1 and $\mathrm{HisCl} 2$ ) [75], and a pHsensitive chloride channel (Figure 3) [76]. The remaining cysLGICs have yet to be functionally characterized. $M$. domestica is the only other insect reported to possess a putative ortholog of $D$. melanogaster cysLGIC, NtR. Insect cysLGICs are of importance as they are targets of widely used insecticides [77], such as phenylpyrazoles (which act on GABA receptors and GluCls), spinosyns and neonicotinoids (which act on nAChRs). The cysLGIC sequence information from diverse species, including agricultural pests, disease vectors and pollinating insects [78-80], provides a valuable starting point for understanding the interactions of insecticides with their targets at the molecular level, as well as enhancing our understanding of mechanisms causing insecticide resistance, and may prove instructive in the future design and development of improved insecticides with enhanced specificity for pest species.

\section{Chemoreceptors}

The olfactory and gustatory abilities of insects depend on many chemoreceptors and associated proteins encoded by at least four major gene families [81]. The odorant binding proteins (OBPs) are small, globular, secreted proteins that transport hydrophobic odorants to the receptors in sensory neuron membranes within sensory sensilla, primarily on the antennae, but also on the maxillary palps and other chemosensory organs [82]. The odorant receptors (ORs) are a relatively recently evolved family within the insect chemosensory superfamily of ligand-gated ion channels that mediate much of olfaction in insects [83]. The gustatory receptors (GRs) mediate much of gustation, especially perception of sugars and bitter tasting compounds, but as the basal family of highly divergent receptors within the superfamily, also mediate some aspects of olfaction, such as perception of carbon dioxide [84]. The ionotropic 


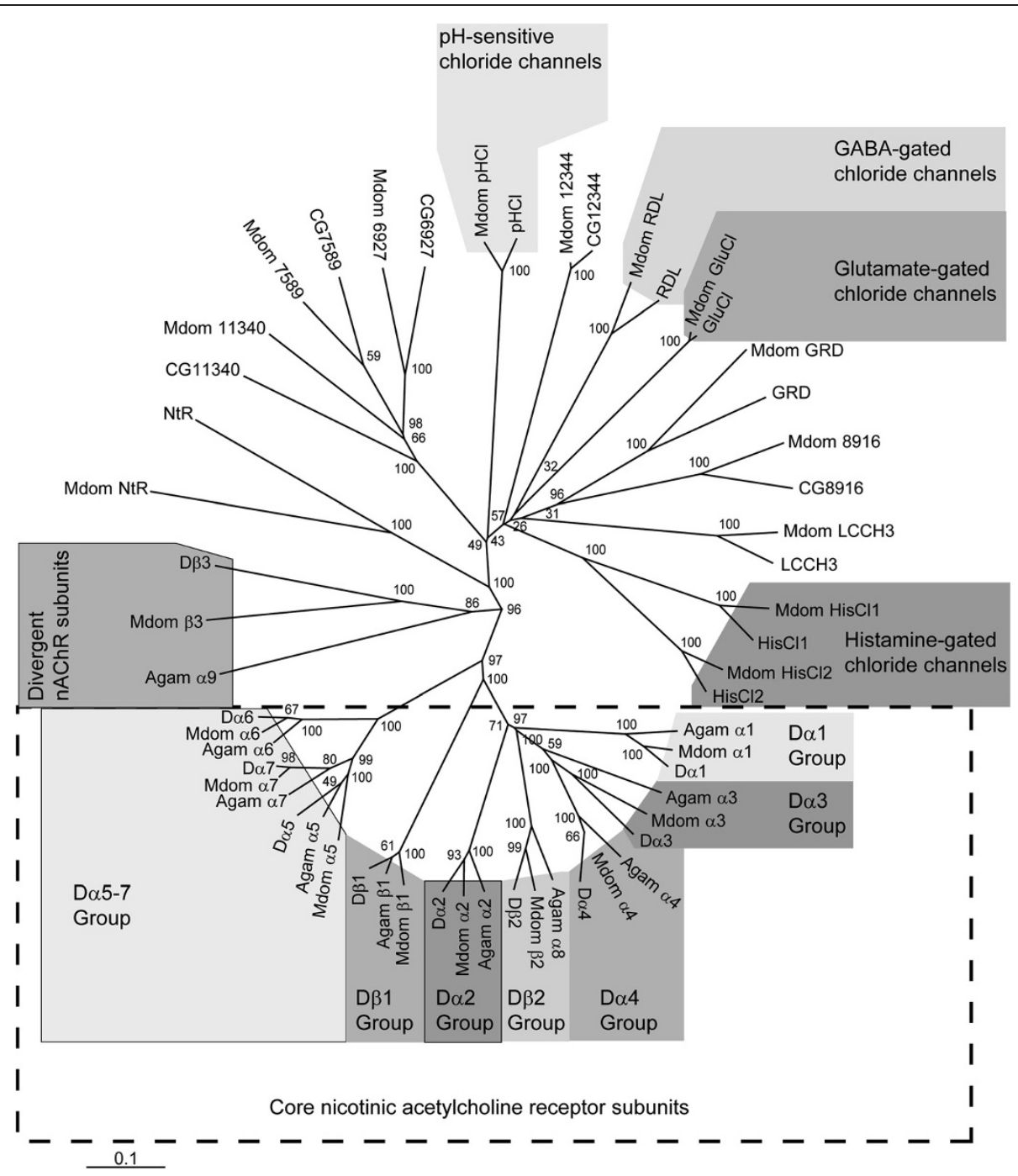

Figure 3 Phylogeny showing relationships of $M$. domestica and D. melanogaster cysLGIC protein sequences. Anopheles gambiae sequences were also included when comparing nAChR sequences. Numbers at each node signify bootstrap values with 100 replicates and the scale bar represents substitutions per site. Genbank ccession numbers for sequences shown in the tree are: A. gambiae Agama1 (AY705394), Agama2 (AY705395), Agama3 (AY705396), Agam a4 (AY705397), Agama5 (AY705399), Agama6 (AY705400), Agama7 (AY705402), Agama8 (AY705403), Agamaß9a (AY705404) and Agamß1 (AY705405); D. melanogaster Da1 (CAA30172), Da2 (CAA36517), Da3 (CAA75688), Da4 (CAB77445), Da5 (AAM13390), Da6 (AAM13392), Da7 (AAK67257), Dß1 (CAA27641), Dß2 (CAA39211), Dß3 (CAC48166), GluCl (AAG40735), GRD (Q24352), HisCl1 (AAL74413), HisCl2 (AAL74414), LCCH3 (AAB27090), the putative cysLGIC subunit Ntr (AF045471), pHCl (NP_001034025), RDL (AAA28556), CG6927 (AAF45992), CG7589 (AAF49337), CG8916 (BT022901), CG11340 (AAF57144), CG12344 (AAF58743); M. domestica Mdoma2 (DQ372062), Mdoma5 (EF203213), Mdoma6 (DQ498130), Mdomß3 (EF203220), MdomRDL (Q75NA5), MdomGluCl (BAD16657). GABA, Y-aminobutyric acid.

receptors (IRs) are a greatly expanded and divergent family of chemoreceptors that evolved from the ionotropic glutamate receptor superfamily in basal animals, and while some function in olfaction, many are involved in gustation [85].

As the obvious comparison for the $M$. domestica repertoire, D. melanogaster has 52 genes encoding OBPs [86], 60 genes encoding 62 ORs and 60 genes encoding 68 GRs via alternative splicing of some loci [87], and 65 genes encoding IRs [85]. We find that the $M$. domestica genome encodes at least 87 OBPs, has 85 genes encoding 86 ORs, 79 genes encoding 103 GRs, and 110 IRs (Additional files 12, 13, 14, 15, and 16). Detailed examination of the relationships of these gene families in these two flies (Additional files 17, 18, 19, and 20) reveals the expected patterns of birth-and-death gene family evolution typical of environmentally relevant genes. As expected, $M$. domestica shares the highly conserved members of these families, such as the OrCo protein that functions with each specific OR to make a 
functional olfactory receptor, and the apparently equivalent IR8a/25a proteins, along with the conserved suites of sugar and carbon dioxide receptors, and some highly conserved bitter taste receptors. In general, however, while there are roughly equal numbers of gene losses and pseudogenes in each species, $M$. domestica has duplicated and retained more genes in each family. These gene subfamily expansions are particularly prominent in the candidate gustatory receptors, especially those implicated in perception of bitter tasting compounds. For example, $M$. domestica has a large, mostly tandem array of 26 genes, one of which is alternatively spliced to encode 11 receptors, that are related to $8 D$. melanogaster GRs implicated in bitter taste that are now spread around that genome. The expansions in the IR family are also primarily in receptors implicated in gustation. $M$. domestica also has large expansions of ORs related to Or45a and Or67d in $D$. melanogaster, receptors involved in repulsion from aversive chemicals in larvae and in perception of a maleproduced pheromone, respectively.

In summary, $M$. domestica has evolved an expanded repertoire of chemoreceptors and associated proteins compared with $D$. melanogaster. This expansion is mostly associated with gustation, specifically perception of bitter tasting compounds. It may be that the more diverse and potentially toxic food sources and larval habitats of $M$. domestica have led to retention and specialization of gene duplicates in these receptor gene subfamilies. Unfortunately, the ligand specificity of most candidate bitter taste receptors in Drosophila have proven difficult to resolve, so it is not yet possible to infer likely ligands for these novel receptors in $M$. domestica.

\section{Sex determination, sex-biased gene expression and the evolution of sex-biased genes}

The dominant female determining $M d$-tra ${ }^{D}$ (Genbank accession GU070694) allele sampled from a Japanese population contains four small deletions and a small insertion in the alternatively spliced sequences and one non-synonymous substitution in the coding region [88]. We sequenced $M d-$ tra $^{D}$ alleles of 22 to 24 individuals from 7 populations sampled across Europe, North America, Asia, Africa and Australia and found $M d$-tra ${ }^{D}$ alleles on all continents. Surprisingly, we detected exactly the same molecular signatures in $M d$-tra ${ }^{D}$ alleles of all populations tested (Figure 4), but different alleles for the non-dominant form, containing insertions or deletions in exon 3. Further studies will be necessary to elucidate the cause for its rapid global dispersion and fixation in autosomal populations. Availability of the genome sequence will facilitate such studies; particularly scans of the Md-tra locus can be conducted to look for more variants.

Genes with sexually dimorphic (sex-biased) expression, much like other sexually dimorphic traits, tend to evolve faster than genes with equal (unbiased) expression in males and females $[89,90]$. Among genes with sex-biased expression, genes expressed in reproductive tissues evolve fastest, particularly those expressed primarily in malelimited organs [91]. The faster evolution of genes with sex-biased expression is likely driven by a combination of positive Darwinian selection and relaxed purifying selection $[89,92]$. Genes with higher expression in males (malebiased) are also more likely than unbiased genes to not have identifiable homologs in comparisons between Drosophila species $[89,93]$, suggesting that genes with malebiased functions are more dispensable or that their protein coding sequences evolve too fast for homolog identification [92].

We used RNA-seq to measure gene expression levels in whole male and female adult flies, and we identified genes with male- or female-biased expression (Additional file 21). Out of 10,096 genes with sufficiently high expression to allow a test contrasting the sexes, 113 have male-biased

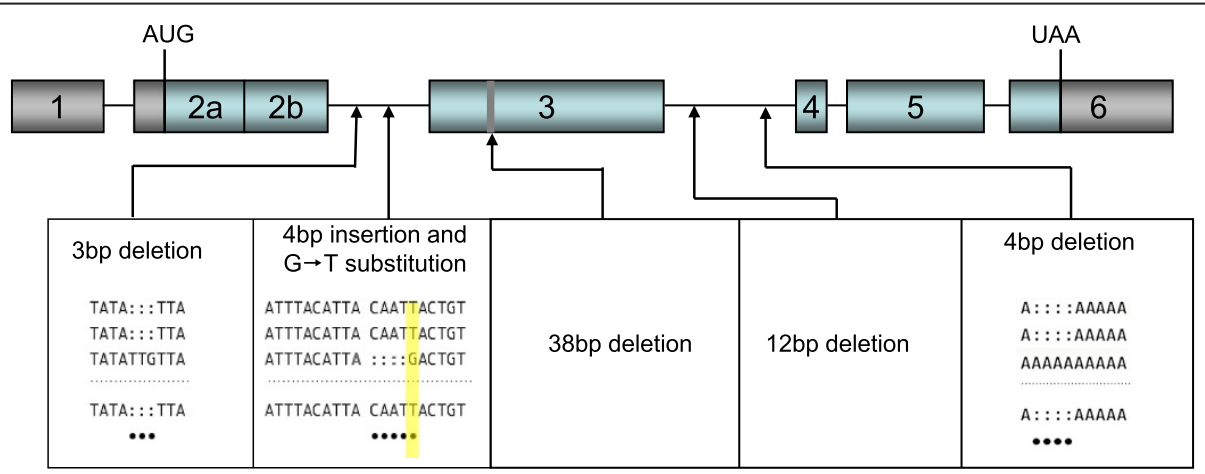

Figure 4 Molecular lesions in $\mathbf{M d}_{\mathbf{d}} \mathbf{t r a}^{\boldsymbol{D}}$ alleles of different populations. Schematic organization of exons in Md-tra. Exon $2 \mathrm{~b}$ and/or exon 3 are included in male $\mathrm{Md}$-tra transcripts and cause premature termination of translation due to the presence of in-frame translational termination signals. In females these exon sequences are skipped, giving rise to transcripts with an intact open reading frame. The positions of the reported $\mathrm{Md}_{\mathrm{d}}$ tra ${ }^{\mathrm{D}}$ sequence variations are indicated by arrows and further details are described in the boxes below [88]. 
expression and 81 have female-biased expression (Table 3). There are no significant differences in GO categories between male-biased, female-biased, and unbiased genes, although this analysis is likely limited by small sample sizes. In Drosophila whole bodies, approximately 10 to $20 \%$ of genes have sex-biased expression [93,94], which is an order of magnitude greater than what we observe in house fly. Drosophila gonads and other reproductive organs make up a substantial portion of adult body mass [95,96], whereas house fly reproductive organs (especially in males) are relatively smaller [97]. Because sex-biased expression in whole bodies is driven primarily by genes that are differentially expressed between male and female reproductive tissues [98], the lower frequency of genes with sex-biased expression in house fly whole bodies could be the result of smaller reproductive organs and/or less severe sexual conflict. Alternatively, we may have less power to detect sex-biased expression in house fly due to low replication or noisy data.

To test the hypothesis that genes with sex-biased expression experience more evolutionary turnover than unbiased genes, we used the ortholog calls described above to divide house fly genes into those with at least one $D$. melanogaster homolog (conserved) and those that are lineage-specific. Not all $M$. domestica genes tested for sexbiased expression were included in the test of homologous genes in D. melanogaster (and vice versa), because of how the data were handled. House fly genes with sex-biased expression are less likely to be conserved than genes with unbiased expression $(P<0.01$, Fisher's exact test $($ FET $))$ (Table 3). Genes with male-biased expression are less likely to be conserved than unbiased genes $(P<0.005$, FET), whereas female-biased genes are as conserved as unbiased genes $(P=0.729$, FET) (Table 3$)$. While malebiased house fly genes have a lower frequency of homology matches to $D$. melanogaster than female-biased genes, this difference is not significant $(P=0.091$, FET). These results support the hypothesis that genes with male-biased expression are gained/lost from the genome at a faster rate than other genes, and/or that genes with male-biased expression have faster evolving proteincoding sequences that evade homology detection.

We next calculated amino acid sequence identity between house fly and D. melanogaster for genes that are singlecopy orthologs to determine whether genes with sex-biased

Table 3 Sex-biased expression of house fly genes and homology with $D$. melanogaster genes

\begin{tabular}{llll}
\hline Sex-bias & Conserved & Lineage-specific & Frequency conserved \\
\hline Male-biased & 88 & 25 & 0.779 \\
Female-biased & 71 & 10 & 0.877 \\
Unbiased & 8,478 & 1,104 & 0.884 \\
\hline
\end{tabular}

expression experience elevated rates of evolution (Figure 5). Genes with male-biased expression are more divergent than both female-biased $(P<0.005$, Mann-Whitney $(\mathrm{MW})$ test) and unbiased $\left(P<10^{-6}\right.$, MW test $)$ genes. There is not a significant difference in evolutionary divergence between female-biased and unbiased genes $(P=0.280$, MW test). These results suggest that at least some of the lineage-specific house fly male-biased genes are the result of genes with male-biased expression evading homology detection because of their faster evolving protein-coding sequences.

We further divided house fly genes with $D$. melanogaster homologs into those that were duplicated specifically in the house fly lineage (remaining single-copy in D. melanogaster) and those that are one-to-one homologs with $D$. melanogaster genes (Table 4). Duplicated genes are more likely to have male-biased expression than single-copy genes $(P<0.005, \mathrm{FET})$, consistent with what has been observed in $D$. melanogaster [99]. Unlike the pattern in $D$. melanogaster, house fly duplicated genes are also more likely to have female-biased expression than single-copy genes $(P<0.05$, FET $)$. In general, house fly duplicated genes are more likely to have sex-biased expression than single-copy genes $(P<0.0005$, FET $)$, and there is no difference in duplication frequency between male- and femalebiased genes $(P=0.665, \mathrm{FET})$. These results suggest that gene duplication is a mechanism for generating both male- and female-biased expression in house fly, which differs from the observation in Drosophila [99].

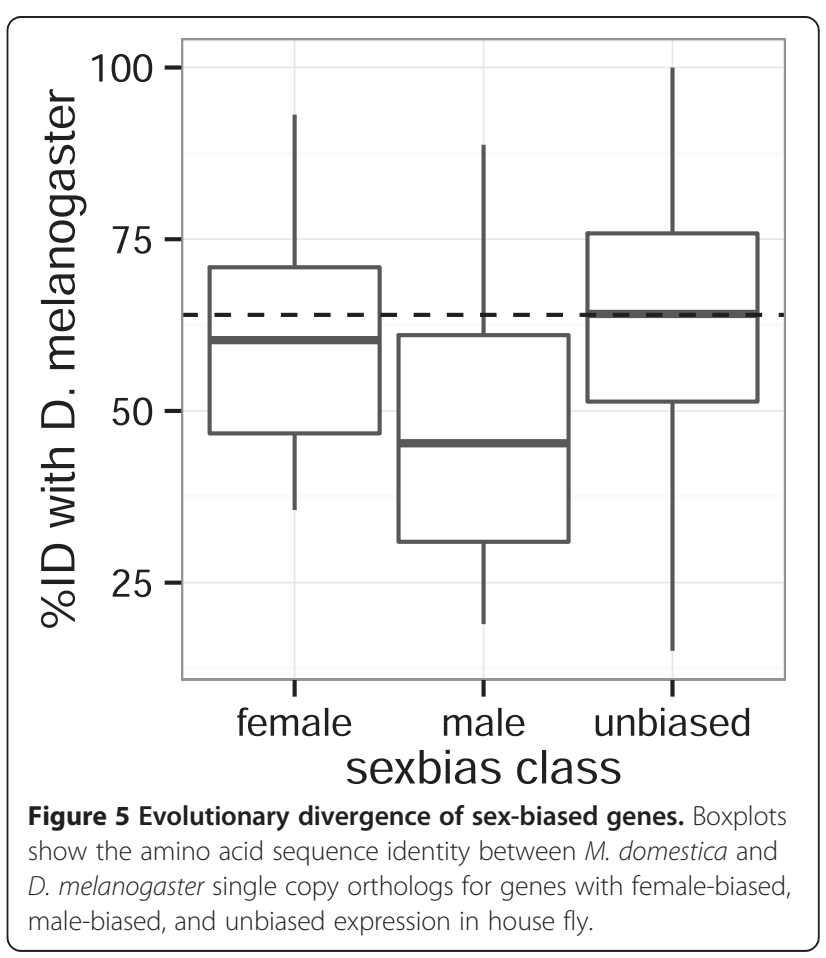


Table 4 Sex-biased expression of house fly genes and duplication status

\begin{tabular}{llll}
\hline Sex-bias & Duplicated & Single-copy & Frequency duplicated \\
\hline Male-biased & 17 & 42 & 0.288 \\
Female-biased & 12 & 39 & 0.235 \\
Unbiased & 832 & 5,782 & 0.126 \\
\hline
\end{tabular}

\section{Actin}

Five actin genes were found in house fly (LOC1019 01018, LOC101887443, LOC101890414, LOC101895248, LOC101888968), one less than found in D. melanogaster. The sequences were highly similar at the amino acid level (95.5 to 99.5\%; Martinez-NW pairwise alignments) and the nucleotide level (84.4 to $96.8 \%)$. Like D. melanogaster each sequence was 1,131 nucleotides in length. The high degree of similarity between these genes suggests that the use of one of these genes as an internal standard for quantitative PCR should be carefully scrutinized to avoid detection of multiple actin genes. The deduced amino acid sequences of LOC101888968 and LOC101895248 were $100 \%$ identical to D. melanogaster actin $5 \mathrm{c}$ and $88 \mathrm{~F}$, respectively. Other orthologs could not be unambiguously identified.

\section{MicroRNA and microRNA machinery}

After mapping all of the miRbase sequences against the $M$. domestica genome, a total of 69 microRNAs (miRNAs) along with their hairpin precursors were predicted to be present in the $M$. domestica genome (Additional file 22). Seven miRNAs had two copies and two had three copies, making a total of at least 81 miRNA loci in the $M$. domestica genome. Within the multiple copy miRNAs, two miRNAs, miR-1-5p and miR-996-5p, had the same hairpin precursors, but were located in two distinct locations of the genome, suggesting a duplication event. In addition to the predicted miRNA, 25 isoforms of 11 genes were predicted to be involved in the transporting, processing and function of miRNAs, socalled miRNA machinery [100] (Additional file 23). These genes include Drosha, DGCR (partner of Drosha), ran-like GTPase, exportin-5, Dicer, multiple argonaute proteins, including one ago-1-like gene with four isoforms, two ago-2-like genes, one with two isoforms and another ago-2-like gene with five isoforms, and one ago-3like gene, and two RISC-loading genes. Similar to other dipteran species, no sid-1 homolog, which is involved in systemic miRNA, was identified in the $M$. domestica genome [101]. However, multiple genes putatively involved in the uptake of exogenous double-stranded RNA were identified; including two eater genes, and one nibbler gene (Additional file 23). Although the biological function of these miRNAs are currently unknown, the availability of bioinformatics information will provide a valuable tool for future studies targeting on the gene regulation in physiological processes [102] of house flies.

\section{Conclusions}

We have sequenced and analyzed the genome of the $M$. domestica using DNA from female flies. This represents the first genome sequence of an insect that lives in intimate association with abundant animal pathogens. The sequenced genome size is $691 \mathrm{Mb}$ and contains 15,345 genes. Compared with $D$. melanogaster, the genome contains a rich resource of shared and novel protein coding genes and a significantly higher amount of repetitive elements.

In comparison to D. melanogaster, the house fly genome has a larger number of genes associated with immune response, detoxification and chemosensation. Relative to $D$. melanogaster there are substantial increases in copy number and diversity of both the recognition and effector components of the immune system in the house fly genome, consistent with life in a pathogen-rich environment. For detoxification genes, there are $146 \mathrm{P} 450$ genes (plus 11 pseudogenes) in $M$. domestica, representing a significant increase relative to D. melanogaster (or G. morsitans) and suggesting the presence of enhanced detoxification capacity in house flies. Relative to $D$. melanogaster, $M$. domestica has also evolved an expanded repertoire of chemoreceptors and odorant binding proteins, many associated with gustation.

The availability of the house fly genome should accelerate the pace of research on this important vector of human and animal diseases. The house fly genome provides a rich resource for enabling work on innovative methods of insect control, for understanding the mechanisms of insecticide resistance, genetic adaptation to high pathogen loads, host parasitoid interactions, and for exploring the basic biology of this important pest. The genome of this species will also serve as a close outgroup to G. morsitans in comparative genomic studies.

\section{Materials and methods}

\section{Genome and transcriptomes}

DNA was extracted [103] from individual unmated adult females of the $M$. domestica aabys strain [104] and used for genome sequencing. The aabys strain was selected because it was inbred (to reduce polymorphisms and thus facilitate the genome assembly), is an XY strain, and because it is a widely disseminated and commonly used strain, particularly for linkage analyses. A total sequence coverage of approximately $90 \times$ was generated from fragment and jumping libraries then assembled using the ALLPATHS-LG assembler [105]. Contaminating contigs, adaptors, ambiguous bases as N's in the sequence and all contigs $200 \mathrm{bp}$ and smaller were removed. The final $M$. domestica 2.0.2 genome sequence is available under the GenBank accession number AQPM00000000.1 and NCBI assembly accession GCA_000371365.1. All genome 
sequences utilized in de novo assembly of $M$. domestica were submitted to the NCBI short read archive (SRA) under accession numbers SRX217932-217940.

RNA was isolated from individual last instar larvae $(\mathrm{n}=1$; accession SRX208995), individual 1-day-old adult males $(\mathrm{n}=2$; accessions SRX208993 and SRX208994) and individual unmated 1-day-old adult females $(\mathrm{n}=2$; accessions SRX208996 and SRX208997) as described previously [106]. Poly(A) + RNA was isolated as a starting input for the Ovation ${ }^{\circ}$ RNASeq System V2 (NuGEN, San Carlos, CA USA). A check of quality was measured with the Agilent Bioanalyzer. From samples that passed our quality control (minimum RNA integrity number (RIN) score of 7), a non-normalized cDNA library was constructed using a modified version of the Ovation ${ }^{\circ}$ RNASeq System V2 [107] that generates strand specificity, an important factor in alignment biases seen with non-directional RNA-seq data. We sequenced each cDNA library (0.125 lane) on an Illumina HiSeq 2000 instrument (approximately 36 Gb per lane) at $100 \mathrm{bp}$ length. These data provided sufficient sequence coverage of the estimated exon content (approximately $29 \mathrm{Mb}$ ) of a $691 \mathrm{Mb}$ assembled house fly genome.

\section{Gene annotation}

The pipeline used for the annotation of house fly is fully documented in the NCBI handbook [108] and is briefly described here. Prior to gene annotation 52\% of the assembly was masked with WindowMasker [109], a wordbased algorithm that identifies repeats de novo. By comparison, masking with the RepeatMasker library would have resulted in only $2.15 \%$ of the genome being masked. The annotation process was initiated by the alignment to the masked genome of publicly available house fly transcripts and RNA-seq from project SRP015949 with Splign [110], and Diptera proteins by ProSplign. Overlapping alignments with compatible frames were assembled into chains and extended or filled-in as needed by the $a b$ initio prediction component of Gnomon to form complete models [137]. The resulting models were then evaluated and retained or discarded based on multiple criteria, including evidence support and homology to existing proteins. Following manual checks we predicted a total house fly gene count of 15,349 , consisting of 14,180 proteincoding genes (with 17,508 transcripts), 1,165 non-coding genes and 4 pseudogenes. The number of genes is comparable to D. melanogaster (15,771) [111]. A total of 3,985 transcripts were filled-in or extended by $a b$ initio prediction for $5 \%$ of their length or more, and 1,375 models were marked partial. The mean number of exons per transcript were estimated to be 4.9 .

\section{Gene ontology}

In total, 17,508 protein sequences were searched against Swiss-Prot with the BLASTp algorithm [40]. The E-value cutoff was set at $10^{-5}$ and taking the best 20 hits for annotation. Blast2GO $[112,113]$ was used to predict the functions of the sequences and assign GO terms. Simplification of the annotation into functional categories was also done by Blast2GO using GO slim. Proteins were summarized at level 2 into three main GO categories (biological process, cellular component, and molecular function) and 33 subcategories.

\section{Defining homology to $D$. melanogaster}

To define homology between $D$. melanogaster and $M$. domestica proteins, we started with an all-against-all BLASTp, using standard parameters and an E-value cutoff of 1e-5. We then filtered hits to remove all hits with similarity below $30 \%$ and at least $70 \%$ alignment coverage (dropping to $40 \%$ if the aligned region is at least 100 amino acids long). After filtering, we converted E-values to scores by taking the negative $\log 10$ (capped at 200), and then for each query computed a minimum score to keep by subtracting 10 from the minimum of the maximum score to the other species or the average of the top 5 hits. After removing hits below the minimum score for each query, we clustered proteins into groups using MCL [114] with the following parameters: -we 2 -force-connected $=y-$-scheme 7 . These are considered homologous groups. This procedure is tuned to be conservative about missing true orthologs at the cost of inflating group size by linking sets of reciprocal best hits into a single group.

To resolve relationships among groups that contain more than one D. melanogaster or $M$. domestica member, we aligned members of each cluster using mafft (with the -auto option) [115], trimmed the resulting alignments with trimal (default options) [116], and then computed trees with phyml [117] using default options. After computing trees for each paralogous group, we used the SDI algorithm implemented in TreeBest [138] and RIO [118] to resolve speciation and duplication events. We split groups that could be completely parsed into smaller orthologous groups, but retained as large families cases with complicated histories, which implied lineage-specific losses at the root of the tree. In many cases these likely resulted from low-confidence basal nodes. For all single copy orthologous gene pairs between $M$. domestica and $D$. melanogaster, we produced protein alignments using mafft [115] with the -auto flag and otherwise default parameters. Rates of protein divergence were calculated for each alignment with PAML version 4.4d [119].

\section{Immune-related genes}

Two complementary computational approaches were used to define the repertoire of immune-related genes in $M$. domestica. The first relied on the well-annotated $D$. melanogaster genome. We curated a list of immune- 
related D. melanogaster proteins from the literature (updated from [47]), and assumed an immune function for proteins in $M$. domestica that are homologous (as defined by the method described above) to proteins with immune function in D. melanogaster. To supplement the homology-based annotations, our second approach applied a HMM originally developed to characterize the mosquito immune system [120]. Using curated alignments of putative immune-related proteins and domains from $D$. melanogaster and two mosquitoes available at ImmunoDB, plus a NIM domain alignment [46], we built HMMs using HMMER [139], and then computed the likelihood of containing each domain for each $M$. domestica predicted protein. After correcting for the number of domains tested, we retained all calls with an E-value $<0.01$, assigning genes to the class with the lowest E-value in cases where a single protein hit multiple domains. The classes included are: several antimicrobial peptides (attacins, cecropins, defensins, diptericins), CLIP-domain serine proteases $(-\mathrm{A},-\mathrm{B},-\mathrm{C}-,-\mathrm{D}$, and $-\mathrm{E})$, serpins, C-type lectins (CTLs) and galectins, beta-glucan binding proteins, peptidoglycan recognition proteins, fibrinogen-related proteins (FREPs), peroxidases, lysozymes, MD2-like receptors, Nimrods, prophenoloxidases, scavenger receptors (A, B, and $\mathrm{C}$ ), thioester-containing proteins, Tolls, spaetzle-like proteins, and Rel-domain proteins. In some cases (for example, SrcA, galectin, FREPs, CLIP-A, CTLs, peroxidases) there is little evidence for an immune role in $D$. melanogaster, but we included them in our analysis given the evidence for an immune role in other metazoans. However, it is important to note that similarity to an HMM cannot guarantee an immune function, as many immune-related proteins in insects share domains with non-immune functions (that is, serine proteases).

\section{Metabolism/detoxification genes}

Primary metabolism of xenobiotics is most commonly carried out by cytochrome P450s, esterases/hydrolases and/or GSTs. To identify these genes two approaches were taken. TBLASTn searches [121] were carried out using all the known sequences of insect P450s, GSTs and esterases. We also searched the annotated genome for appropriately named sequences.

\section{Cys-loop ligand-gated ion channels and actin}

Putative $M$. domestica cys-loop ligand-gated ion channel subunits were identified by searching the annotated genome with TBLASTn [121] using protein sequences of every member of the D. melanogaster cys-loop ligand-gated ion channel superfamily. The neighbor-joining method [122], available with the Clustal X program [123], was used to construct a phylogenetic tree, which was then viewed using
TreeView [140]. Actin sequences were identified using the same approach.

\section{Chemoreceptors}

The GR family was manually annotated using methods employed for other insect genomes [87]. Briefly, TBLASTn searches were performed using all $D$. melanogaster GRs as queries, and gene models were manually assembled in TextWrangler [141]. Additional details are provided in Additional file 16.

\section{Sex determination, sex-biased gene expression and the evolution of sex-biased genes}

$M d$-tra ${ }^{D}$ females were collected from seven populations in different countries and different continents: Trabzon (Turkey), Faverges (France), Santa Fé (Spain), Tansania, North Carolina (USA), Osaka (Japan) and Ipswich (Australia).

RNA-seq reads of two biological replicates each of adult males and females were aligned to the reference genome using TopHat2 (v2.0.8b) [124] with the default parameters. We tested for differential expression between the male and female samples using Cuffdiff version 2.1.1 [125] with the default parameters and a false discovery rate of 0.05 .

\section{microRNA and microRNA machinery}

The mature miRNAs from the miRbase database (release 20) [126] were tested against the $M$. domestica supercontigs using miRdeep2, version 2.0.0.5 [127,128]. The known D. melanogaster miRNAs were used as the reference mature miRNA sets [129-131]. The miRNA machinery was primarily predicted from the Gnomon annotated $M$. domestica genome. Additional gene prediction for genes putatively involved in double-stranded RNA uptake was predicted by BLASTp comparison [121] to known genes in the D. melanogaster genome (v. dmel_r5.9_FB2008_06 [60]).

\section{Additional files}

Additional file 1: Table S1. Gene families with the largest increases in copy number in the $M$. domestica genome, relative to $D$. melanogaster. Additional file 2: Table S2. Transcript coverage varies among insect genomes as a result of assembly contiguity, dictated by repeat composition.

Additional file 3: Table S3. Comparison of the $M$. domestica genome to a previously published transcriptome of $M$. domestica.

Additional file 4: Figure S1. Gene Ontology analysis of the $M$. domestica genome.

Additional file 5: Table S4. Comparative gene ontology between $M$. domestica (Md) and D. melanogaster (Dm).

Additional file 6: Table S5. Cytochrome P450 genes in the M. domestica genome with reference to the cytochrome P450 genes present in the D. melanogaster genome. 
Additional file 7: Table S6. Predicted cytochrome P450 genes in the Glossina genome.

Additional file 8: Table S7. Predicted cytochrome P450 genes in the M. domestica genome.

Additional file 9: Table S8. Predicted GSTs and esterases in the $M$. domestica genome.

Additional file 10: Figure S2. Unrooted neighbor-joining tree showing the phylogenetic analysis of GSTs of $M$. domestica (MD, red) in relation to GSTs from D. melanogaster (DM, green). MUSCLE software was used to perform multiple sequence alignment [132]. The neighbor-joining method was applied to the multiple sequence alignment using MEGA 5.0 [133]. Distance bootstrap values of $>70 \%$ (1,000 replicates) are indicated at the corresponding nodes. The GST classes are colored distinctively: microsomal, turquoise; sigma, dark blue; omega, orange; zeta, dark red; theta, pink; delta, light blue and epsilon, light green. Sequences and the names for the D. melanogaster GST genes were taken from FlyBase [60].

Additional file 11: Table S9. CysLGICs in the house fly, M. domestica. Additional file 12: Table S10. Details of MdOBP family genes and proteins. Additional file 13: Table S11. Details of MdOR family genes and proteins. Additional file 14: Table S12. Details of MdGR family genes and proteins. Additional file 15: Table S13. Details of MdIR family genes and proteins. Additional file 16: Chemoreceptors, including protein sequences.

Additional file 17: Figure S3. Phylogenetic tree of the $M$. domestica and D. melanogaster ORs. This is a corrected distance tree with the OrCo orthologs as the out-group to root the tree. The OrCo orthologs were declared as the out-group to root the tree, based on the basal position of this gene in the OR family in analysis of the entire chemoreceptor superfamily in D. melanogaster [87]. Comments on major gene lineages are on the right. Suffixes after the gene/protein names include: FIX, sequence fixed with raw reads; INT, internal sequence missing; JOI, gene model joined across scaffolds; multiple suffixes are abbreviated to single letters. The $M$. domestica and D. melanogaster gene/protein names are highlighted in blue and red, respectively, as are the branches leading to them to emphasize gene lineages. Bootstrap support level in percentage of 10,000 replications of uncorrected distance analysis is shown above major branches. Inferred ancestral and orthologous lineages are highlighted in double thickness. Suffixes after the gene/protein names are: NTE, amino terminus missing; CTE, carboxyl terminus missing; PSE, pseudogene.

Additional file 18: Figure S4. Phylogenetic tree of the M. domestica and D. melanogaster OBPs. This is a corrected distance tree and was rooted at the midpoint in the absence of a simple obvious out-group. See Additional file 17 legend for other details.

Additional file 19: Figure S5. Phylogenetic tree of the M. domestica and $D$. melanogaster IRs. This is a corrected distance tree rooted with IR8a/25a as the out-group, based on their highly conserved sequences and ancestral position in the family [134-136]. See Additional file 17 legend for other details.

Additional file 20: Figure S6. Phylogenetic tree of the $M$. domestica and D. melanogaster GRs. This is a corrected distance tree rooted by declaring the distantly related and divergent carbon dioxide and sugar receptor subfamilies as the out-groups. The relationships within the sugar receptor subfamily are not accurate in this tree because many of these genes in M. domestica are only partially assembled. See Additional file 17 legend for other details.

Additional file 21: Table S14. Test of sex-biased expression in $M$. domestica using cuffdiff [122].

Additional file 22: Table S15. Locations of putative microRNA and their predicted precursor hairpins from the M. domestica genome.

Additional file 23: Table S16. MicroRNA machinery and genes predicted to be involved in exogenous double-stranded RNA uptake in M. domestica.

\section{Abbreviations}

AMP: antimicrobial peptide; bp: base pair; FET: Fisher's exact test; FREP: fibrinogen-related protein; GABA: $\gamma$-aminobutyric acid; GO: Gene
Ontology; GR: gustatory receptor; GST: glutathione S-transferase; HMM: hidden Markov model; IR: ionotropic receptor; miRNA: microRNA; MW: Mann-Whitney; nAChR: nicotinic acetylcholine receptor; OBP: odorant binding protein; OR: odorant receptor; Tep: thioester-containing protein.

\section{Competing interests}

The authors declare that they have no competing interests.

\section{Authors' contributions}

$J G S, N L$, and AGC conceived of the study. CAL prepared the genomic DNA. FDR prepared the RNA. WCW, PM, CT and RKW prepared the sequencing libraries, directed the sequencing and assembled the genome. Annotation of the genome was by TM and FT-N. SK carried out the GO analyses. TBS manually annotated and analyzed the immune-related genes. WZR, ML, NL, DN and JGS manually annotated and analyzed the detoxification genes. AK and DBS manually annotated and analyzed the LGIC genes. HMR, SDG and KKOW manually annotated and analyzed the chemoreceptors and odorant binding protein genes. RPM analyzed the sex-biased genes. JGS and SK annotated the actin genes. $L B, D B, L v d Z$ and $M H$ carried out the analysis of Md-tra. WRR, ML and NL manually annotated and analyzed the miRNA genes. All authors read and approved the final manuscript.

\section{Acknowledgements}

We thank the production sequencing group of The Genome Institute at Washington University for library construction, sequencing and data curation. This work was supported by NIH-NHGRI grant 5U54HG00307907 to RKW, Hatch Project NYC-139416 to JGS and multistate project S-1030 to JGS.

\section{Author details}

'Department of Entomology, Comstock Hall, Cornell University, Ithaca, NY 14853, USA. ${ }^{2}$ The Genome Institute, Washington University School of Medicine, St Louis, MO 63108, USA. ${ }^{3}$ Evolutionary Genetics, Center for Ecological and Evolutionary Studies, University of Groningen, Groningen 9747, The Netherlands. ${ }^{4}$ Institute of Molecular Life Sciences, University of Zurich, Zurich 8057, Switzerland. ${ }^{5}$ Department of Molecular Biology and Genetics, Cornell University, Ithaca, NY 14853, USA. ${ }^{6}$ Department of Entomology, University of Illinois at Urbana-Champaign, 505 S. Goodwin Ave, Urbana, IL 61801, USA. ${ }^{7}$ Department of Biological and Medical Sciences, Faculty of Health and Life Sciences, Oxford Brookes University, Oxford OX3 OBP, UK. ${ }^{8}$ Department of Entomology and Plant Pathology, Auburn University, Auburn, AL 36849, USA. 'Department of Biology and Biochemistry, University of Houston, Houston, TX 77204, USA. ${ }^{10} \mathrm{NCBI} / \mathrm{NLM} / \mathrm{NIH} / \mathrm{DHHS}, 45$ Center Drive, Room 5AS.43D-82, Bethesda, MD 20892, USA. " ${ }^{1}$ Department of Microbiology, Immunology and Biochemistry, University of Tennessee Health Science Center, Memphis, TN 38163, USA. ${ }^{12}$ Department of Organismic and Evolutionary Biology, Harvard University, Cambridge, MA 02139, USA. ${ }^{13}$ Department of Medicine, Wolfson Institute for Biomedical Research, University College London, Gower Street, London WC1E 6BT, UK. ${ }^{14} \mathrm{NCBI} /$ NLM/NIH/DHHS, 45 Center Drive, Room 4AS.37D-82, Bethesda, MD 20892, USA.

Received: 25 April 2014 Accepted: 10 September 2014 Published online: 14 October 2014

\section{References}

1. Scott HG, Lettig KS: Flies of Public Health Importance and their Control. Washington, DC: US Government Printing Office; 1962.

2. Keiding J: The House Fly - Biology and Control. World Health Organization (WHO), Vector Biology and Control Division; 1986. WHO/NBC/86.937.

3. Greenberg B: Flies and disease. Sci Am 1965, 213:92-99.

4. Sasaki T, Kobayashi M, Agui N: Epidemiological potential of excretion and regurgitation by Musca domestica (Diptera: Muscidae) in the dissemination of Escherichia coli 0157: H7 to food. J Med Entomol 2000, 37:945-949.

5. Rahuma N, Ghenghesh KS, Ben-Aissa R, Elamaari A: Carriage by the housefly (Musca domestica) of multiple-antibiotic-resistant bacteria that are potentially pathogenic to humans, in hospital and other urban environments in Misurata, Libya. Ann Trop Med Parasitol 2005, 99:795-802.

6. Macovei L, Zurek L: Ecology of antibiotic resistance genes: Characterization of enterococci from houseflies collected in food settings. Appl Environ Microbiol 2006, 72:4028-4035. 
7. Boulesteix G, Le Dantec P, Chevalier B, Dieng M, Niang B, Diatta B: Role of Musca domestica in the transmission of multiresistant bacteria in the centres of intensive care setting in sub-Saharan Africa. Ann Fr Anesth Reanim 2005, 24:361-365.

8. Graczyk TK, Knight R, Gilman RH, Cranfield MR: The role of non-biting flies in the epidemiology of human infectious diseases. Microbes Infec 2001 3:231-235.

9. Sundin GW: Evolution and selection of antibiotic and pesticide resistance: a molecular genetic perspective. In Molecular Genetics and Evolution of Pesticide Resistance. Edited by Brown TM. Washington, DC: American Chemical Society; 1996:97-105 [ACS Symposium Series. 645th edition].

10. Maisnier-Patin S, Andersson Dl: Adaptation to the deleterious effects of antimicrobial drug resistance mutations by compensatory evolution. Res Microbiol 2004, 155:360-369.

11. Trachoma [http://www.who.int/topics/trachoma/en/]

12. Mündi K: Housefly, an Everyday Monster. Colorado Springs, CO USA: Winstar Studios; 1994

13. Kelling FJ, Biancaniello G, den Otter CJ: Electrophysiological characterization of olfactory cell types in the antennae and palps of the housefly. J Insect Physiol 2002, 48:997-1008.

14. Kelling FJ, Biancaniello G, den Otter CJ: Effect of age and sex on the sensitivity of antennal and palpal olfactory cells of houseflies. Ent Exp Appl 2003, 106:45-51.

15. Darbro JM, Mullens BA: Assessing insecticide resistance and aversion to methomyl-treated toxic baits in Musca domestica L (Diptera: Muscidae) populations in southern California. Pest Manag Sci 2004, 60:901-908.

16. Hanley ME, Dunn DW, Abolins SR, Goulson D: Evaluation of (Z)-9-tricosene baited targets for control of the housefly (Musca domestica) in outdoor situations. J Appl Entomol 2004, 128:478-482.

17. Group NGW: Functional and evolutionary insights from the genomes of three parasitoid Nasonia species. Science 2010, 327:343-348.

18. Scott JG, Liu N, Kristensen M, Clark AG: A case for sequencing the genome of the house fly, Musca domestica (Diptera: Muscidae). J Med Entomol 2009, 46:175-182.

19. Hiroyoshi T: Some new mutants and linkage groups of the house fly. J Econ Entomol 1960, 53:985-990.

20. Tsukamoto M, Baba Y, Hiraga S: Mutations and linkage groups in Japanese strains of the housefly. Jpn J Genet 1961, 36:168-174.

21. Nickel CA, Wagoner DE: Mutants on linkage gropus 3 and 4 of the house fly. Ann Entomol Soc Am 1974, 67:775-776.

22. Hiroyoshi T: Some new mutants and revised linkage maps of the housefly, Musca domestica L. Japan J Genet 1977, 52:275-288.

23. Milani R, Rubini PG, Franco MG: Sex-determination in the housefly. Genet Agaria 1967, 21:385-411.

24. Hiroyoshi T: Sex-limited inheritance and abnormal sex ratio in strains of the housefly. Genetics 1964, 50:373-385.

25. Dübendorfer A, Hediger M, Burghardt G, Bopp D: Musca domestica, a window on the evolution of sex-determining mechanisms in insects. Int J Dev Biol 2002, 46:75-79.

26. Denholm I, Franco MG, Rubini PG, Vecchi M: Identification of a male determinant on the $\mathrm{X}$ chromosome of housefly (Musca domestica L.) populations in South-East England. Genet Res Camb 1983, 42:311-322.

27. Bull JJ, Charnov EL: Changes in the heterogametic mechanism of sex determination. Heredity 1977, 39:1-14.

28. Tomita T, Wada Y: Multifactorial sex determination in natural populations of the housefly (Musca domestica) in Japan. Jpn J Genet 1989, 64:373-382.

29. Franco $M G$, Rubini $P G$, Vecchi M: Sex-determinants and their distribution in various populations of Musca domestica L. of Western Europe. Genet Res Camb 1982, 40:279-293.

30. Inoue H, Fukumori $Y$, Hiroyoshi T: Mapping of autosomal male-determining factors of the housefly, Musca domestica L., by means of sex reversal. Jpn J Genet 1983, 58:451-461.

31. Hamm RL, Scott JG: Changes in the frequency of $Y^{M}$ versus III ${ }^{M}$ in the house fly, Musca domestica L., under field and laboratory conditions. Genet Res Camb 2008, 90:1-6.

32. Kozielska M, Feldmeyer B, Pen I, Weissing FJ, Beukeboom LW: Are autosomal sex-determining factors of the housefly (Musca domestica) spreading north? Genet Res Camb 2008, 90:157-165.

33. Hamm R, Shono T, Scott JG: A cline in frequency of autosomal males is not associated with insecticide resistance in house fly (Diptera: Muscidae). J Econ Entomol 2005, 98:171-176.
34. Hamm RL, Scott JG: A high frequency of male determining factors in male Musca domestica L. (Diptera: Muscidae) from Ipswich, Australia. J Med Entomol 2009, 46:169-172.

35. Schmidt R, Hediger M, Roth S, Nothiger R, Dübendorfer A: The Y-chromosomal and autosomal male-determining $M$ factors of Musca domestica are equivalent. Genetics 1997, 147:271-280.

36. Wagoner DE: Presence of male determining factors found on three autosomes in the house fly, Musca domestica. Nature 1969, 223:187-188.

37. Bier VK, Müller W: DNS-Messungen bei Insekten und eine Hypothese über retardierte Evolution und besonderen DNS-Reichtum im Tierreich. Biologisches Zentralblatt 1969, 88:425-449.

38. Gao J, Scott JG: Use of quantitative real-time PCR to estimate the size of the house fly (Musca domestica) genome. Insect Mol Biol 2006, 15:835-837.

39. Li M, Reid WR, Zhang L, Scott JG, Gao X, Kristensen M, Liu N: A whole transcriptomal linkage analysis of gene co-regulation in insecticide resistant house flies, Musca domestica. BMC Genomics 2013, 14:803.

40. Altschul SF, Madden TL, Schäffer AA, Zhang J, Zhang Z, Miller W, Lipman DJ: Gapped BLAST and PSI-BLAST: a new generation of protein database search programs. Nucleic Acids Res 1997, 25:3389-3402

41. Slater GS, Birney E: Automated generation of heuristics for biological sequence comparison. BMC Bioinformatics 2005, 6:31

42. Imler J-L: Overview of Drosophila immunity: a historical perspective. Dev Comp Immunol 2014, 42:3-15.

43. Ferrandon D, Imler J-L, Hetru C, Hoffman JA: The Drosophila systemic immune response: sensing and signalling during bacterial and fungal infections. Nat Rev Immunol 2007, 7:862-874.

44. Kurata S: Peptidoglycan recognition proteins in Drosophila immunity. Dev Comp Immunol 2014, 41:36-41.

45. Blandin S, Levashina EA: Thioester-containing proteins and insect immunity. Mol Immunol 2004, 40:903-908.

46. Somogyi K, Sipos B, Pénzes Z, Kurucz E, Zsámboki J, Hultmark D, Andó I: Evolution of genes and repreats in the Nimrod superfamily. Mol Biol Evol 2008, 25:2337-2347.

47. Sackton TB, Lazzaro BP, Schlenke TA, Evans JD, Hultmark D, Clark AG: Dynamic evolution of the innate immune system in Drosophila. Nat Genet 2007, 39:1461-1468

48. Sackton TB, Clark AG: Comparative profiling of the transcriptional response to infection in two species of Drosophila by short-read cDNA sequencing. BMC Genomics 2009, 10:259.

49. Vizioli J, Bulet P, Hoffmann JA, Kafatos FC, Müller HM, Dimopoulos G: Gambicin: a novel immune responsive antimicrobial peptide from the malaria vector Anopheles gambiae. Proc Natl Acad Sci U S A 2001, 98:12630-12635.

50. Casteels P, Ampe C, Jacobs F, Vaeck M, Tempst P: Apidaecins: antibacterial peptides from honeybees. EMBO J 1989, 8:2387-2391

51. Sackton TB, Werren JH, Clark AG: Characterizing the infection-induced transcriptome of Nasonia vitripennis reveals a preponderance of taxonomically-restricted immune genes. PLoS One 2013, 8:e83984.

52. Tian C, Gao B, Fang Q, Ye G, Zhu S: Antimicrobial peptide-like genes in Nasonia vitripennis: a genomic perspective. BMC Genomics 2010, 11:187.

53. Scott JG: Thinking Beyond Detoxification. In Recent Advances in Insect Physiology, Toxicology and Molecular Biology. Edited by Liu N. Kerala, India: Research Signpost; 2008:117-124.

54. Adams MD, Celniker SE, Holt RA, Evans CA, Gocayne JD, Amanatides PG, Scherer SE, Li PW, Hoskins RA, Galle RF, George RA, Lewis SE, Richards S, Ashburner M, Henderson SN, Sutton GG, Wortman JR, Yandell MD, Zhang Q, Chen LX, Brandon RC, Rogers YH, Blazej RG, Champe M, Pfeiffer BD, Wan KH, Doyle C, Baxter EG, Helt G, Nelson CR, et al: The genome sequence of Drosophila melanogaster. Science 2000, 287:2185-2195.

55. Tijet N, Helvig C, Feyereisen R: The cytochrome P450 gene superfamily in Drosophila melanogaster: annotation, intron-exon organization and phylogeny. Gene 2001, 262:189-198.

56. Ono H, Rewitz K, Shinoda T, Itoyama K, Petryk A, Rybczynski R, Jarcho M, Warren J, Marques G, Shimell MJ, Gilbert LI, O'Connor MB: Spook and spookier code for stage-specific components of the ecdysone biosynthetic pathway in Diptera. Dev Biol 2006, 298:555-570.

57. Guittard E, Blais C, Maria A, Parvy J, Pasricha S, Lumb C, Lafont R, Daborn P, Dauphin-Villemant C: CYP18A1, a key enzyme of Drosophila steroid hormone inactivation, is essential for metamorphosis. Dev Biol 2011, 349:35-45. 
58. Sztal T, Chung H, Berger S, Currie PD, Batterham P, Daborn PJ: A cytochrome P450 conserved in insects is involved in cuticle formation. PLoS One 2012, 7:e36544

59. Nelson DR: The Cytochrome P450 Homepage. Hum Genomics 2009, 4:59-65.

60. St Pierre SE, Ponting L, Stefancsik R, McQuilton P, the FlyBase Consortium: FlyBase 102 - advanced approaches to interrogating FlyBase. Nucleic Acids Res 2014, 42:D780-D788.

61. Artimo P, Jonnalagedda M, Arnold K, Baratin D, Csardi G, de Castro E, Duvaud S, Flegel V, Fortier A, Gasteiger E, Grosdidier A, Hernandez C, loannidis V, Kuznetsov D, Liechti R, Moretti S, Mostaguir K, Redaschi N, Rossier G, Xenarios I, Stockinger H: ExPASy: SIB bioinformatics resource portal. Nucleic Acids Res 2012, 40:W597-W603.

62. Fayyazuddin A, Zaheer MA, Hiesinger PR, Bellen HJ: The nicotinic acetylcholine receptor Dalpha7 is required for an escape behavior in Drosophila. PLOS Biol 2006, 4:e63.

63. El Hassani AK, Dupuis JP, Gauthier M, Armengaud C: Glutamatergic and GABAergic effects of fipronil on olfactory learning and memory in the honeybee. Invert Neurosci 2009, 9:91-100.

64. Li Y, Zhou Z, Zhang X, Tong H, Li P, Zhang ZC, Jia Z, Xie W, Han J: Drosophila neuroligin 4 regulates sleep through modulating GABA transmission. J Neurosci 2013, 33:15545-15554.

65. Thompson AJ, Lester HA, Lummis SC: The structural basis of function in Cys-loop receptors. Q Rev Biophys 2010, 43:449-499.

66. Jones AK, Bera AN, Lees K, Sattelle DB: The cys-loop ligand-gated ion channel gene superfamily of the parasitoid wasp, Nasonia vitripennis. Heredity 2010, 104:247-259.

67. Jones A, Brown L, Sattelle D: Insect nicotinic acetylcholine receptor gene families: from genetic model organism to vector, pest and beneficial species. Invert Neurosci 2007, 7:67-73.

68. Gao J-R, Deacutis JM, Scott JG: Characterization of the nicotinic acetylcholine receptor subunit gene Mda2 from the house fly, Musca domestica. Arch Insect Biochem Physiol 2007, 64:30-42.

69. Gao J-R, Deacutis JM, Scott JG: Characterization of the nicotinic acetylcholine receptor subunits Mdalpha5 and Mdbeta3 on autosome 1 of Musca domestica indicate they are not involved in spinosad resistance. Insect Mol Biol 2007, 16:691-701.

70. Gao J-R, Deacutis JM, Scott JG: The nicotinic acetylcholine receptor subunit Mda6 from Musca domestica is diversified via post transcriptional modification. Insect Mol Biol 2007, 16:325-334.

71. Corringer PJ, Le Novere N, Changeux JP: Nicotinic receptors at the amino acid level. Annu Rev Pharmacol Toxicol 2000, 40:431-458.

72. Jones AK, Grauso M, Sattelle DB: The nicotinic acetylcholine receptor gene family of the malaria mosquito, Anopheles gambiae. Genomics 2005 85:176-187.

73. Eguchi $Y$, Ihara M, Ochi E, Shibata $Y$, Matsuda K, Fushiki S, Sugama $H$, Hamasaki Y, Niwa H, Wada M, Ozoe F, Ozoe Y: Functional characterization of Musca glutamate- and GABA-gated chloride channels expressed independently and coexpressed in Xenopus oocytes. Insect Mol Biol 2006 15:773-783

74. Buckingham S, Sattelle D: GABA receptors of insects. In Comprehensive Molecular Insect Science. Edited by Gilbert LI, latrou K, Gill SS. Boston: Elsevier; 2005:142.

75. Gisselmann G, Pusch H, Hovemann BT, Hatt H: Two cDNAs coding for histamine-gated ion channels in D. melanogaster. Nat Neurosci 2002, 5:11-12.

76. Schnizler K, Saeger B, Pfeffer C, Gerbaulet A, Ebbinghaus-Kintscher U, Methfessel C, Franken EM, Raming K, Wetzel CH, Saras A, Pusch H, Hatt H, Gisselmann G: A novel chloride channel in Drosophila melanogaster is inhibited by protons. J Biol Chem 2005, 280:16254-16262.

77. Raymond-Delpuch V, Matsuda K, Sattelle BM, Rauh JJ, Sattelle DB: Ion channels: molecular targets of neuroactive insecticides. Invert Neurosci 2005, 5:119-133.

78. Dale RP, Jones AK, Tamborindeguy C, Davies TG, Amey JS, Williamson S, Wolstenholme A, Field LM, Williamson MS, Walsh TK, Sattelle DB: Identification of ion channel genes in the Acyrthosiphon pisum genome. Insect Mol Biol 2010, 19:141-153.

79. Jones A, Marshall J, Blake A, Buckingham S, Darlison MG, Sattelle DB: Sgß1, a novel locust (Schistocerca gregaria) non-a nicotinic acetylcholine receptor-like subunit with homology to the Drosophila melanogaster Dß1 subunit. Invert Neurosci 2005, 5:147-155.
80. Jones AK, Raymond-Delpech V, Thany SH, Gauthier M, Sattelle DB: The nicotinic acetylcholine receptor gene family of the honey bee, Apis mellifera. Genome Res 2006, 16:1422-1430.

81. Touhara K, Vosshall LB: Sensing odorants and pheromones with chemosensory receptors. Annu Rev Physiol 2009, 71:307-332.

82. Pelosi P, Zhou JJ, Ban LP, Calvello M: Soluble proteins in insect chemical communication. Cell Mol Life Sci 2006, 63:1658-1676.

83. Su CY, Menuz K, Carlson JR: Olfactory perception: receptors, cells, and circuits. Cell 2009, 139:45-59.

84. Liman ER, Zhang YV, Montell C: Peripheral coding of taste. Neuron 2014, 81:984-1000.

85. Rytz R, Croset V, Benton R: lonotropic receptors (IRs): chemosensory ionotropic glutamate receptors in Drosophila and beyond. Insect Biochem Mol Biol 2013, 43:888-897.

86. Vieira FG, Rozas J: Comparative genomics of the odorant-binding and chemosensory protein gene families across the Arthropoda: origin and evolutionary history of the chemosensory system. Genome Biol Evol 2011, 3:476-490.

87. Robertson HM, Warr CG, Carlson JR: Molecular evolution of the insect chemoreceptor gene superfamily in Drosophila melanogaster. Proc Natl Acad Sci U S A 2003, 100:14537-14542.

88. Hediger M, Henggeler C, Meier N, Perez R, Saccone G, Bopp D: Molecular characterization of the key switch $F$ provides a basis for understanding the rapid divergence of the sex-determining pathway in the housefly. Genetics 2010, 184:155-170.

89. Ellegren H, Parsch J: The evolution of sex-biased genes and sex-biased gene expression. Nat Rev Genet Genet 2007, 8:689-698.

90. Parsch J, Ellegren $\mathrm{H}$ : The evolutionary causes and consequences of sex-biased gene expression. Nat Rev Genet Genet 2013, 14:83-87.

91. Meisel RP: Towards a more nuanced understanding of the relationship between sex-biased gene expression and rates of protein coding sequence evolution. Mol Biol Evol 2011, 28:1893-1900.

92. Mank JE, Ellegren H: Are sex-biased genes more dispensible? Biol Lett 2009, 5:409-412.

93. Zhang $Y$, Sturgill D, Parisi M, Kumar S, Oliver B: Constraint and turnover in sex-biased gene expression in the genus Drosophila. Nature 2007, 450:233-237.

94. Gnad F, Parsch J: Sebida: a database for the functional and evolutionary analysis of genes with sex-biased expression. Bioinformatics 2006, 22:2577-2579.

95. Demerec M: Biology of Drosophila. New York: John Wiley \& Sons; 1950.

96. Hartenstein V: Atlas of Drosophila Development. Cold Spring Harbor, NY: Cold Spring Harbor Laboratory Press; 1993.

97. Hewitt CG: The Housefly Musca domestica. Its Structure, Habits, Development, Relation to Disease and Control. Cambridge, London: University Press; 1914.

98. Parisi M, Nuttall R, Edwards P, Minor J, Naiman D, Lü J, Doctolero M, Vainer M, Chan C, Malley J, Eastman S, Oliver B: A survey of ovary-, testis-, and soma-biased gene expression in Drosophila melanogaster adults. Genome Biol 2004, 5:R40

99. Wyman MJ, Cutter AD, Rowe L: Gene duplication and the evolution of sexual dimorphism. Evolution 2012, 66:1556-1566.

100. Wilson RC, Doudna JA: Molecular Mechanisms of RNA Interference. Annu Rev Biophys 2013, 42:217-239.

101. Gu L, Knipple DC: Recent advances in RNA interference research in insects: implications for future insect pest management strategies. Crop Prot 2013, 45:36-40.

102. Ambros $V$ : The functions of animal microRNA. Nature 2004, 431:350-355.

103. Rinkevich FD, Zhang L, Hamm RL, Brady SG, Lazzaro BP, Scott JG: Frequencies of the pyrethroid resistance alleles of VssC1 and CYP6D1 in house flies from the eastern United States. Insect Mol Biol 2006, 15:157-167.

104. Takada Y, Hiroyoshi T, Hirano M: Linkage group analysis of permethrin resistance in the Miyakonojo colony of the housefly, Musca domestica $\mathrm{L}$. (Diptera: Muscidae). Appl Entomol Zool 1988, 23:122-126.

105. Gnerre S, Maccallum I, Przybylski D, Ribeiro FJ, Burton JN, Walker BJ, Sharpe T, Hall G, Shea TP, Sykes S, Berlin AM, Aird D, Costello M, Daza R, Williams L, Nicol R, Gnirke A, Nusbaum C, Lander ES, Jaffe DB: High-quality draft assemblies of mammalian genomes from massively parallel sequence data. Proc Natl Acad Sci U S A 2011, 108:1513-1518.

106. Rinkevich FD, Scott JG: Limitations of RNAi of a6 nicotinic acetylcholine receptor subunits for assessing the in vivo sensitivity to spinosad. Insect Sci 2013, 20:101-108. 
107. NuGEN [http://www.nugen.com/nugen/]

108. The NCBI Handbook [Internet]: Eukaryotic Genome Annotation Pipeline. In 2nd edition. [http://www.ncbi.nlm.nih.gov/books/NBK169439/]

109. Morgulis A, Gertz EM, Schaffer AA, Agarwala R: WindowMasker: window-based masker for sequenced genomes. Bioinformatics 2006, 22:134-141.

110. Kapustin Y, Souvorov A, Tatusova T, Lipman D: Splign: algorithms for computing spliced alignments with identification of paralogs. Bio/ Direct 2008, 3:20.

111. NCBI Genome: Drosophila melanogaster (fruit fly). [http://www.ncbi.nlm. nih.gov/genome/?term=drosophila+melanogaster]

112. Conesa A, Götz S, García-Gómez JM, Terol J, Talón M, Robles M: Blast2GO: a universal tool for annotation, visualization and analysis in functional genomics research. Bioinformatics 2005, 21:3674-3676.

113. Götz S, García-Gómez JM, Terol J, Williams TD, Nagaraj SH, Nueda MJ, Robles M, Talón M, Dopazo J, Conesa A: High-throughput functional annotation and data mining with the Blast2GO suite. Nucleic Acids Res 2008, 36:3420-3435.

114. MCL - a cluster algorithm for graphs. [http://micans.org/mcl/]

115. Katoh K, Standley DM: MAFFT multiple sequence alignment software version 7: improvements in performance and usability. Mol Biol Evol 2013, 30:772-780.

116. Capella-Gutierrez S, Silla-Martinez JM, Gabaldon T: trimAl: a tool for automated alignment trimming in large-scale phylogenetic analyses. Bioinformatics 2009, 25:1972-1973.

117. Guindon S, Dufayard JF, Lefort V, Anisimova M, Hordijk W, Gascuel O: New algorithms and methods to estimate maximum-likelihood phylogenies: Assessing the performance of PhyML 3.0. Systematic Biol 2010, 59:307-321.

118. Zmasek CM, Eddy SR: RIO: Analyzing proteomes by automated phylogenomics using resampled inference of orthologs. BMC Bioinformatics 2002, 3:14.

119. Yang Z: PAML 4: phylogenetic analysis by maximum likelihood. Mol Biol Evol 2007, 24:1586-1591.

120. Waterhouse RM, Kriventseva EV, Meister S, Xi Z, Alvarez KS, Bartholomay LC, Barillas-Mury C, Bian G, Blandin S, Christensen BM, Dong Y, Jiang H, Kanost MR, Koutsos AC, Levashina EA, Li J, Ligoxygakis P, Maccallum RM, Mayhew GF, Mendes A, Michel K, Osta MA, Paskewitz S, Shin SW, Vlachou D, Wang L, Wei W, Zheng L, Zou Z, Severson DW, et al: Evolutionary dynamics of immune-related genes and pathways in disease-vector mosquitoes. Science 2007, 316:1738-1743.

121. Altschul SF, Gish W, Miller W, Myers EW, Lipman DJ: Basic local alignment search tool. J Mol Biol 1990, 215:403-410.

122. Saitou N, Nei M: The neighbor-joining method: a new method for reconstructing phylogenetic trees. Mol Biol Evol 1987, 4:406-425.

123. Larkin MA, Blackshields G, Brown NP, Chenna R, McGettigan PA, McWilliam H, Valentin F, Wallace IM, Wilm A, Lopez R, Thompson JD, Gibson TJ, Higgins DG: Clustal W and Clustal X version 2.0. Bioinformatics 2007, 23:2947-2948

124. Kim D, Pertea G, Trapnell C, Pimentel H, Kelley R, Salzberg SL: TopHat2: accurate alignment of transcriptomes in the presence of insertions, deletions and gene fusions. Genome Biol 2013, 14:R36.

125. Trapnell C, Hendrickson DG, Sauvageau M, Goff L, Rinn JL, Pachter L: Differential analysis of gene regulation at transcript resolution with RNA-seq. Nat Biotechnol 2013, 31:46-53.

126. miRBase [http://mirbase.org/]

127. Friedländer MR, Mackowiak SD, Li N, Chen W, Rajewsky N: miRDeep2 accurately identifies known and hundreds of novel microRNA genes in seven animal clades. Nucleic Acids Res 2012, 40:37-52.

128. Friedländer MR, Chen W, Adamini C, Maaskola J, Einspanier R, Knespel S, Rajewsky N: Discovering microRNAs from deep sequencing data unsing miRDeep. Nat Biotechnol 2008, 26:407-415.

129. Kozomara A, Griffiths-Jones S: miRBase: integrating microRNA annotation and deep-sequencing data. Nucleic Acids Res 2011, 39:D152-D157.

130. Griffiths-Jones S, Saini HK, van Dongen S, Enright AJ: miRBase: tools for microRNA genomics. Nucleic Acids Res 2008, 36:D154-D158.

131. Griffiths-Jones S: The microRNA registry. Nucleic Acids Res 2004, 32:D109-D111.

132. Edgar RC: MUSCLE: multiple sequence alignment with high accuracy and high throughput. Nucleic Acids Res 2004, 32:1792-1797.

133. Tamura K, Peterson D, Peterson N, Stecher G, Nei M, Kumar S: MEGA5: Molecular evolutionary genetics analysis using maximum likelihood, evolutionary distance, and maximum parsimony methods. Mol Biol Evol 2011, 28:2731-2739.

134. Benton R, Vannice KS, Gomez-Diaz C, Vosshall LB: Variant ionotropic glutamate receptors as chemosensory receptors in Drosophila. Cell 2009, 136:149-162.

135. Croset V, Rytz R, Cummins SF, Budd A, Brawand D, Kaessmann H, Gibson TJ, Benton R: Ancient protostome origin of chemosensory ionotropic glutamate receptors and the evolution of insect taste and olfaction. PLoS Genet 2010, 6:e1001064.

136. Grosjean Y, Rytz R, Farine J-P, Abuin L, Cortot J, Jefferis GSXE, Benton R: An olfactory receptor for food-derived odours promotes male courtship in Drosophila. Nature 2011, 478:236-240.

137. Gnomon: http://www.ncbi.nlm.nih.gov/genome/guide/gnomon.shtml.

138. TreeSoft: http://treesoft.sourceforge.net/treebest.shtml.

139. HMMER http://hmmer.janelia.org/

140. Java Treeview http://jtreeview.sourceforge.net/.

141. TextWrangler http://www.barebones.com/products/textwrangler/.

doi:10.1186/s13059-014-0466-3

Cite this article as: Scott et al:: Genome of the house fly, Musca domestica L., a global vector of diseases with adaptations to a septic environment. Genome Biology 2014 15:466.

\section{Submit your next manuscript to BioMed Central and take full advantage of:}

- Convenient online submission

- Thorough peer review

- No space constraints or color figure charges

- Immediate publication on acceptance

- Inclusion in PubMed, CAS, Scopus and Google Scholar

- Research which is freely available for redistribution 